\title{
SISTEM KENDALI ROTARY KAMERA CCTV BERBASIS ARDUINO
}

\author{
Ilham \\ Teknik Informatika STMIK AKBA \\ E-mail:ilham@akba.ac.id
}

\begin{abstract}
ABSTRAK
Penelitian dilakukan untuk merancang kendali Rotary kamera CCTV dan di implimentasikan pada program aplikasi delphi sebagai interface. Dalam perancangan system dibagi atas dua bagian yaitu perancangan perangkat keras dan perancangan perangkat lunak. Dalam perancangan perangkat keras sistem disusun atas 6 blok utama yaitu, bagian unit pemroses pusat (mikrokotroler) berupa modul Arduino uno, bagian pemroses data dari kamera CCTV berupa modul Arduino Ethernet Shield, bagian Motor servo, bagian Switch hub, bagian modul kamera CCTV dan Laptop atau PC.Hasil penelitian ini menunjukkan bahwa sistem dapat bekerja dengan baik sesuai dengan tujuan penelitian yang dilakukan. Sistem Kendali Rotary kamera CCTV yang dikendalikan melalui program aplikasi delphi sebagai interface dapat menggerakkan kamera CCTV dengan pergerakan posisi $0-180^{\circ}$. Dari pengujian yang dilakukan kecepatan putaran memiliki variasi yang berbeda. Ini disebabkan dengan pemberian delay pada masing-masing putaran. Semakin kecil delay yang diberikan semakin cepat putaran kamera yang dihasilkan, berdasarkan hasil pengujian delay terendah yang diberikan sebesar 20 kecepatan putaran rata-rata yang dihasilkan dari tiga kali percobaan yaitu 3,46 detik.
\end{abstract}

Kata kunci : Sistem Kendali, Arduino, CCTV.

\section{Pendahuluan}

Pada jaman teknologi yang begitu maju saat ini, sistem kendali memiliki peranan penting dalam kehidupan manusia dan dalam perkembangan ilmu dan teknologi. Sistem kendali dalam kehidupan manusia memberikan sangat banyak kemudahan. Hal ini banyak ditemui dalam dunia industri seperti proses-proses dalam pabrik dan industri modern [1]. Untuk menunjang perkembangan infrastruktur industri modern yang lebih efisien dan handal, terutama mesin-mesin canggih yang digunakan dalam proses produksi harus dalam kondisi dan performa yang benarbenar sempurna untuk menjaga kuantitas dan kualitas produksi [2].

Awal mula pengendali dibuat dengan menggunakan komponen elektronik analog. Perkembangan teknologi elektronika yang begitu cepat mempengaruhi komponen kendali yang dulunya menggunakan perangkat elektronika analog mulai tergantikan dengan perangkat elektronika digital. Walaupun dalam penerapannya tidak semua sistem kendali analog dirubah ke dalam sistem digital, tapi dalam pemrosesan datanya sudah dilakukan secara digital. Dengan penerapan komponen digital, pemrosesan data lebih mudah dan akurat. Hal ini disebabkan telah banyak tersedia komponenkomponen yang bekerja secara digital dengan teknologi tinggi.

Dalam penerapannya sebagai pengendali, komponen-komponen digital dirangkai sedemikian rupa dan disesuaikan dengan kondisi bagian yang akan dikendalikan. Dalam penelitian ini objek 
yang akan dikendalikan berupa kamera closed circuit television (CCTV). Dimana rotary atau putaran kamera CCTV dapat dikendalikan.

Kendali rotary atau putaran kamera CCTV dilakukan dengan menggunakan perangkat elektronika yaitu mikrokontroler sebagai pusat kendali dan motor servo sebagai komponen yang akan dikendalikan sebagai pemutar kamera CCTV dan output kamera cetv akan ditampilkan dalam bentuk Interface menggunakan Delphi. Dalam sistem kendali Rotary kamera CCTV dalam penelitian yang dilakukan menggunakanmikrokontroler Arduino Uno. Penerapan sistem kendali rotary kamera CCTV diimplementasikan pada lahan parkir Kampus STMIK AKBA.

\section{II.SISTEM KENDALI}

Dalam sistem pengendali dikenal sistem pengendali loop terbuka atau open-loop control system dan sistem pengendali loop tertutup atau closed-loop control system [3]. Masing-masing sistem mempunyai cara kerja yang berbeda. Akan tetapi dalam praktiknya kedua sistem ini dapat saling mendukung satu sama lain.

Sistem pengendali loop terbuka yaitu sistem pengendali yang sinyal luaran tidak berpengaruh terhadap aksi pengendalian. Hal ini dikarenakan didalam sistem pengendali terbuka tidak terdapat proses umpan balik sinyal output yang menuju ke sinyal input. Model sistem pengendali loop terbuka dapat dilihat pada gambar 1 .

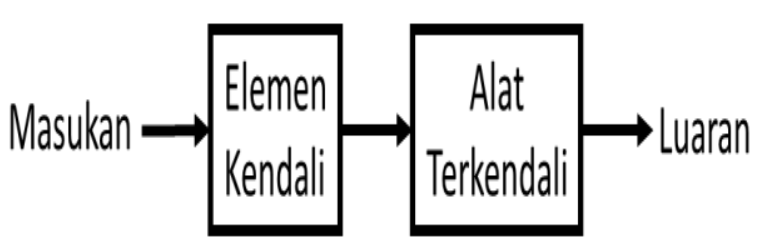

Gambar 1. Sistem loop terbuka

Sistem pengendali loop tertutup yaitu sistem pengendali yang sinyal luaran mempunyai pengaruh langsung terhadap aksi pengendalian, yang menjadi ciri utama dari pengendalian loop tertutup ada nya sinyal umpan balik. Model sistem pengendali loop tertutup dapat dilihat pada gambar 2.

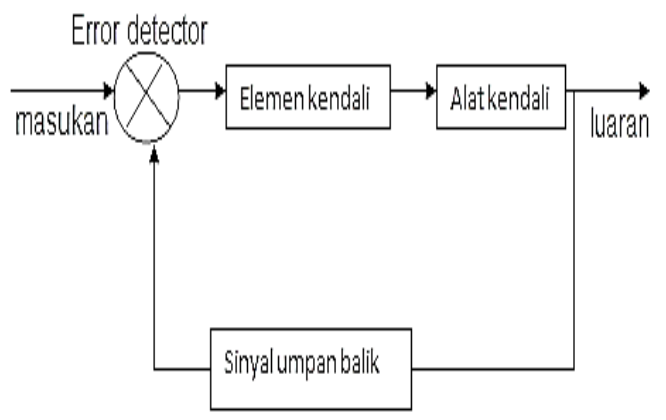

Gambar 2. Sistem loop tertutup

\section{III.KAMERA CCTV}

Kameraclosed circuit television (CCTV) merupakan televisijalur tertutup yang hanya dapat diakses oleh pemasang. Sistem kerja kamera closed circuit television (CCTV) mengirimkan data berupa gambar video dan suara ke sebuah monitor atau video recorder [4].Fungsi dan tujuan pemasangan closed circuit television (CCTV)adalah :

a. Deterance atau factor pencegahan : pelaku kriminal sering kali mengurungkan niat atau takut setelah melihat kamera closed circuit television (CCTV) terpasang.

b. Monitoring atau pemantauan : closed circuit television (CCTV) berguna untuk mengawasi keadaan dan kegiatan di sebuah lokasi.

c. Intensify atau peningkatan kinerja : keberadaan closed circuit television (CCTV) terbukti meningkatkan kinerja karyawan secara signifikan.

d. Investigation atau penyelidikan : closed circuit television (CCTV) menunjang penyelidikan tindak kejahatan.

e. Evidence atau bukti : hasil rekaman closed circuit television (CCTV) dapat menjadi bukti tindak kejahatan dan kriminal. 


\section{MOTOR SERVO}

Motor servo adalah sebuah motor listrik dengan sistem umpan balik tertutup dimana posisi dari motor akan kembali kerangkaian kontrol yang ada di dalam motor servo. Motor ini terdiri dari sebuah motor dc, serangkain gear, potensiometer, dan rangkaian kontrol. Potensiometer berfungsi untuk menentukan batas sudut dari putaran servo [5].

Secara umum terdapat 2 jenis motor servo, yaitu motor servo standar dan motor servo continuous. Motor servo tipe standar hanya mampu berputar 180 derajat. Motor servo standar sering di pakai pada sistem robotika misalnya untuk membuat robot arm (robot lengan), sedangkan servo motor continuous dapat berputar sebesar 360derajat.Motor servo continuous sering dipakai untuk mobile robot.

Motor servo merupakan sebuah motor dc kecil yang diberi sistem gear dan potensiometer sehingga dia dapat menempatkan "horn" servo pada posisi yang di kehendaki. Karena motor ini menggunakan sistem close loop sehingga posisi "horn" yang dikehendaki bisa di pertahankan, "horn" pada motor servo ada dua jenis, yaitu horn " $\mathrm{x}$ " dan horn berbentuk bulat. Bentuk dari motor Servo dapat dilihat pada gambar 3 .

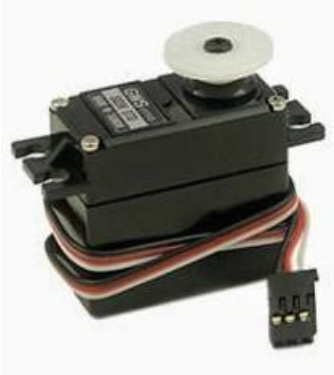

Servo Dengan Horn Bulat

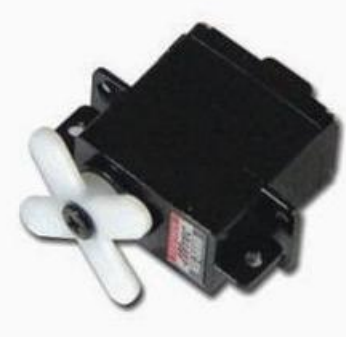

Servo Dengan Horn X
Gambar 3. Motor Servo

Pengendalian gerakan batang motor servo dapat dilakukan dengan menggunakan metode PWM (pulse width modulation). Teknik ini menggunakan sistem lebar pulsa untuk mengendalikan putaran motor, sudut dari sumbu motor servo diatur berdasarkan lebar pulsa yang dikirim melalui kaki sinyal dari kabel motor.

\section{V.ARDUINO UNO}

Arduino uno adalah papan mikrokontroler berbasis Atmega328 yang memliki 14 pin digital input/output (dimana 6 pin dapat digunakan sebagai output pwm), 6 input, clock speed 16mhz, koneksi usb, jack listrik, header icsp, dan tombol reset [5]. Board ini menggunakan daya yang terhubung komputer dengan kabel usb atau daya eksternal dengan adaptor ac-dc atau baterai.

Arduino uno adalah sebuah platform dari physical computing yang bersifat open source [6]. Arduino tidak hanya sekedar sebuah alat pengembangan, tetapi kombinasi dari hardware, bahasa pemrograman dan Integrated Development Environment (IDE) yang canggih. IDE adalah sebuah software yang sangat berperan untuk menulis program, mengcompile menjadi kode biner dan mengupload ke dalam memory microcontroller. Spesifikasi board arduino Uno dapat dilihat pada tabel 1 .

Tabel 1. Spesifikasi Board Arduino Uno

\begin{tabular}{|l|l|}
\hline Mikrokontroler & Atmega328 \\
\hline Tegangan operasi & 5 volt \\
\hline Tegangan input (disarankan) & 7 volt - 12 volt \\
\hline Batas tegangan input & 6 volt -20 volt \\
\hline Pin digital i/o & 14 (dimana 6 pin output pwm) \\
\hline Pin analog input & 6 \\
\hline Arus dc per i/o pin & 40 ma \\
\hline Arus dc untuk pin 3.3v & 50 ma \\
\hline Flash memory & $32 \mathrm{~kb}$ (Atmega328), dimana $0,5 \mathrm{~kb}$ \\
\hline Clock & digunakan oleh bootloeder \\
\hline Sram & $2 \mathrm{~kb}$ (Atmega328) \\
\hline Eeprom & $1 \mathrm{~kb}$ (Atmega328) \\
\hline
\end{tabular}


Bentuk dari Board Arduino Uno dapat dilihat pada gambar 4 .

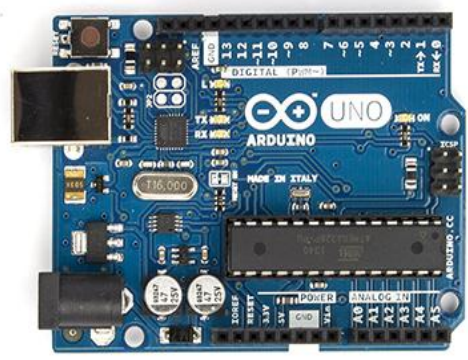

Gambar 4. Board Arduino Uno

Agar board arduino uno dapat terhubung dengan internet maka perlu ditambahkan dengan menggunakan Modul Arduino Ethernet Shield. Adapun Modul Arduino Ethernet Shield yang digunakan dalam merancang sistem yang dibangun yaitu Arduino ethernet shield berbasis chip Ethernet Wiznet W5100. Wiznet W5100 merupakan jaringan provider (IP) yang mendukung TCP dan UDP. Dengan menggunakan library ethernet untuk penulisan atau upload sketch, modul ini bisa digunakan untuk terhubung dengan internet. Adapun modul Arduino Ethernet Shield dapat dilihat pada gambar 5.

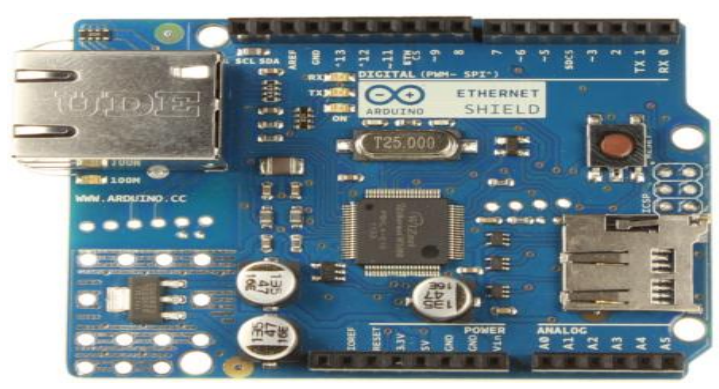

Gambar 5. Board Arduino Uno

\section{Perancangan Perangkat Keras}

Dalam perancangan perangkat keras sistem disusun atas 6 blok utama yaitu, bagian unit pemroses pusat (mikrokotroler) berupa modul Arduino uno, bagian pemroses data dari kamera CCTV berupa modul Arduino Ethernet Shield, bagian Motor servo, bagian Switch hub, bagian modul kamera CCTV dan Laptop atau PC. Blok diagram perancangan dapat dilihat pada gambar 6 .

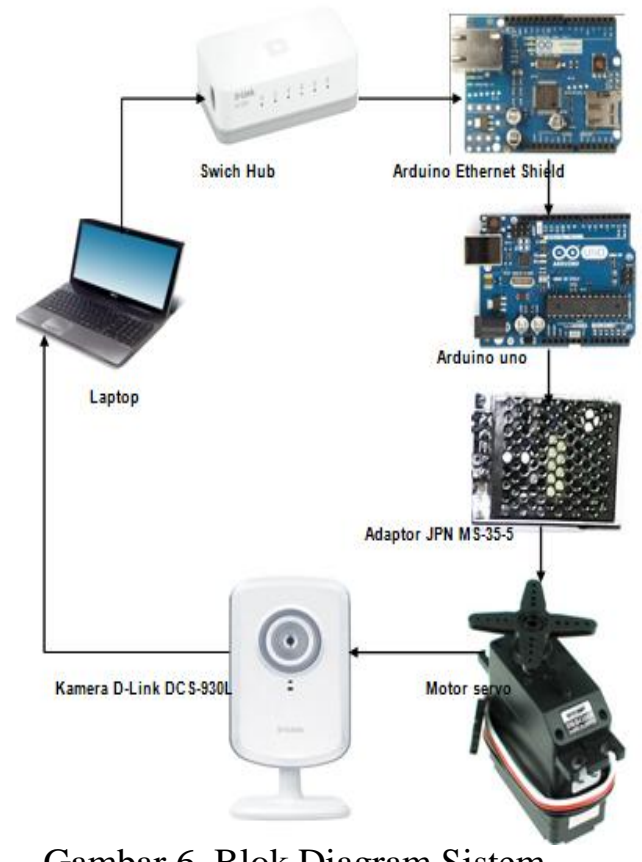

Gambar 6. Blok Diagram Sistem

\section{VII.Perancangan Perangkat lunak}

Agar sistem yang dibangun dapat berjalan sesuai dengan tujuan yang diinginkan maka dilakukan perancangan perangkat lunak dengan menyusun Flowchart sistem. Adapun Flowchart sistem dapat dilihat pada gambar 7 .

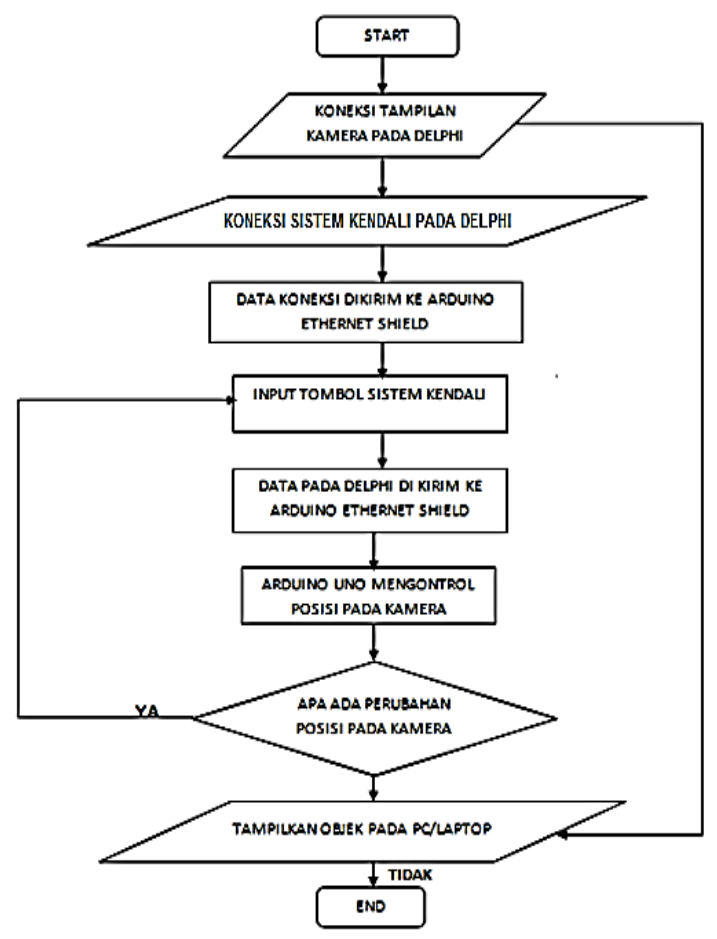

Gambar 7. Flowchart Sistem 


\section{Hasil Perancangan}

Dalam melakukan percobaan pada sistem yang dibangun hal pertama yang dilakukan adalah melakukan inisialisasi port pada komputer agar sistem dapat berkomunikasi antara komputer dan modul arduino uno. Untuk mengetahui port yang dideteksi oleh komputer dapat dilihat pada gambar 8 .

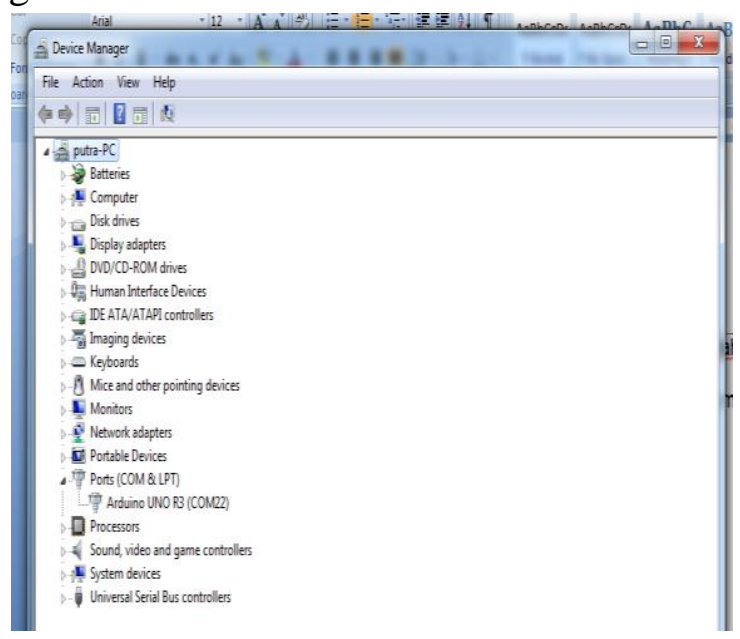

Gambar 8. Identifikasi Port

Setelah identifikasi port yang dilakukan selanjutnya yaitu mengkonfigurasi kamera. Kamera yang digunakan dalam sistem yang dibangun menggunakan kamera D-Link DC S-930L. adapun hasil tampilan kamera pada interface yang dihasilkan dapat dilihat pada gambar 9 .

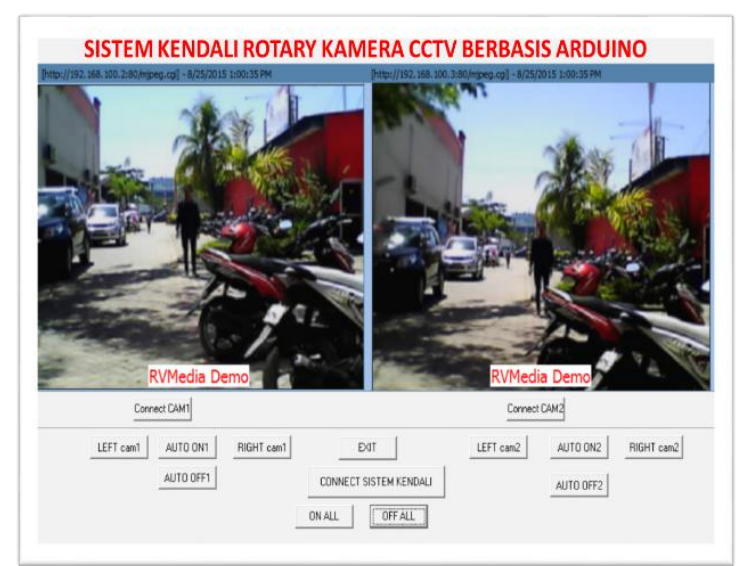

Gambar 9. Hasil kamera pada tampilan Interface

Tahapan selanjutnya yaitu pengujian putaran kamera CCTV, adapun hasil pengujian putaran Kamera CCTV dapat dilihat pada tabel 2 .

Tabel 2. Hasil Pengujian Putaran Kamera CCTV

\begin{tabular}{|c|l|l|c|c|l|}
\hline \multirow{2}{*}{ No } & \multirow{2}{*}{ Waktu } & \multicolumn{3}{|c|}{ Hasil pengujian 0-180 derajat } & \multirow{2}{*}{$\begin{array}{c}\text { Hasil } \\
\text { Rata-Rata }\end{array}$} \\
\cline { 3 - 5 } & & Putaran1 & Putaran2 & Putaran3 & \\
\hline $\mathbf{1}$ & Delay (20) & 3.30 detik & 3.31 detik & 3.76 detik & 3.46 detik \\
\hline $\mathbf{2}$ & Delay (50) & 9.19 detik & 9.10 detik & 9.38 detik & 9.22 detik \\
\hline $\mathbf{3}$ & Delay (70) & 12.68 detik & 12.75 detik & 12.53 detik & 12.65 detik \\
\hline $\mathbf{4}$ & Delay (100) & 17.90 detik & 18.16 detik & 18.20 detik & 18.09 detik \\
\hline $\mathbf{5}$ & Delay (150) & 26.92 detik & 27.10 detik & 27.16 detik & 27.06 detik \\
\hline $\mathbf{6}$ & Delay (200) & 35.75 detik & 36.35 detik & 36.20 detik & 36.1 detik \\
\hline $\mathbf{7}$ & Delay (250) & 45.10 detik & 46.53 detik & 46.91 detik & 46.18 detik \\
\hline $\mathbf{8}$ & Delay (500) & 90.10 detik & 90.99 detik & 91.05 detik & 90.71 detik \\
\hline $\mathbf{9}$ & Delay (750) & 135.79 detik & 145.01 detik & 146.05 detik & 142.28 detik \\
\hline $\mathbf{1 0}$ & Delay (1000) & 183 detik & 180 detik & 181 detik & 181.33 detik \\
\hline & & & & \\
\hline
\end{tabular}

Dari hasil pengujian didapatkan kecepatan putaran dari $0-180^{\circ}$ pada saat menekan tombol pada interface memiliki variasi kecepatan yang berbeda tergantung delay yang diberikan. Delay terendah yang diberikan sebesar 20 dan delay tertinggi yang diberikan sebesar 1000. Dalam pengujian dilakukan tiga kali percobaan setiap delay. Adapun kecepatan responsif tiap-tiap percobaan berbeda-beda diakibatkan pengukuran waktu masih menggunakan secara manual yakni menggunakan stopwatch yang dioperasikan secara manual pula. Dari hasil percobaan selisih antara percobaan 1 , 2 dan 3 masing-masing delay tidak terlalu signifikan perbedaan waktu yang dihasilkan. Dari hasil pengujian dapat disimpulkan semakin kecil delay yang diberikan semakin cepat putaran yang dihasilkan.

\section{Penutup}

Kasimpulan yang dapat diperoleh dari perancangan dan analisis system kendali rotary Kamera CCTV berbasis Arduino yaitu : 
1. Perancangan sistem Kendali Rotary kamera CCTV dirancang dengan menggunakan Arduino Uno yang di tambahkan arduino Ethernet Shield yang dihubungkan dengan komputer sebagai interface menggunakan Borland delphi dapat melakukan pengendalian kamera baik secara otomatis maupun manual dengan pergerakan $0-180^{\circ}$ dan dapat menampilkan objek dari sudut yang berbeda.

2. Kecepatan Putaran yang dihasilkan memiliki variasi yang berbeda berdasarkan delay yang diberikan, semakin kecil delay yang diberikan respon putaran kamera semakin cepat, berdasarkan hasil pengujian delay 20 didapatkan rata-rata kecepatan putaran dari $0-180^{\circ}$ sebesar 3,46 detik sebanyak 3 kali percobaan.

\section{DAFTAR PUSTAKA}

[1] Ilham. 2014. Kendali Linear Quadratic Regulator (LQR) Pada Motor Induksi 3 Phasa Dengan Direct Torque Control (DTC). Jurnal Inspiration Vol. 4 No. 2.

[2] Endro Wahjono. Soebagio. 2019. Fuzzi Logic Direct Torque Control Untuk Motor Induksi Yang digunakan Pada kendaraan Listrik (Electrik Vehicle).Politeknik Elektronika Negeri Surabaya.

[3] Wahana Komputer. 2009. Aplikasi Cerdas Menggunakan Delpi. Jakarta : ANDI.

[4] Cahyadi, Budi. 2014.Membuat Webcam Sebagai CCTV Melalui Smartphone Android. Yogyakarta : ANDI.

[5] Syahwil, Muhammad. 2013.Panduan Mudah Simulasi dan Praktek Mikrokontroler Arduino.Yogyakarta : ANDI.
[6] Saefullah, Asep, dkk. 2015.Sistem Kontrol Robot Pemindah Barang Menggunakan Aplikasi Android Berbasis Arduino Uno. Jurnal Teknik Elektro Vol.8 No. 2, 45-56. 